\title{
Participação Social e protagonismo em saúde mental: a insurgência de um coletivo
}

Social participation and protagonism in mental health: the rising of a collective

Diogo Faria Corrêa da Costa', Simone Mainieri Paulon²

' Mestre em Psicologia Social e Institucional pela Universidade Federal do Rio Grande do Sul (UFRGS) - Porto Alegre (RS), Brasil. Professor do Curso de Psicologia da Faculdade Integrada de Santa Maria (FISMA) - Santa Maria (RS), Brasil.

diogofccosta@yahoo.com.br

2 Doutora em Psicologia Clínica pela Pontifícia Universidade Católica de São Paulo (PUC SP) - Sao Paulo (SP), Brasil. Professora do Programa de Pós-Graduaçáo em Psicologia Social e Institucional da UFRGS - Porto Alegre (RS), Brasil.

simone.paulon@ufrgs.br
RESUMO Este artigo busca contribuir para a Reforma Psiquiátrica, propondo-se a analisar um de seus atuais desafios: o exercício de protagonismo e participação social de usuários em saúde mental. Para tanto, descreve uma pesquisa, sustentada metodologicamente na cartografia, em espaços instituídos de participação, em um Centro de Atenção Psicossocial de município da fronteira oeste do Rio Grande do Sul, onde foram utilizadas as seguintes ferramentas de pesquisa: observação participante, diário de campo e entrevistas com gestores, trabalhadores e usuários. Entre seus resultados, o conceito de coletivo indicou a potência de um novo arranjo participativo, capaz de dialogar com as noções de autonomia e protagonismo, constituindo-se enquanto plano existencial fértil para o exercício de protagonizar em saúde mental.

PALAVRAS CHAVE: Saúde mental; Participação social; Políticas públicas.

\begin{abstract}
This article seeks to contribute to the Psychiatric Reform, aiming at the analysis of one of its current challenges: the exercise of protagonism and social participation of mental health users. For this, it describes a research, methodologically based on the cartography method, supported by established spaces of participation in a Psychosocial Attention Center of a town in the western border of Rio Grande do Sul, using the following research tools: participant observation, field diary and interviews with managers, workers and users. Among its findings, the concept of collective indicated the power of a new participatory arrangement, capable of dealing with the notions of autonomy and protagonism, which acts as a breeding ground for the exercise of protagonism in mental health.
\end{abstract}

KEYWORDS: Mental health; Social participation; Public policies. 


\section{Introdução}

O ano de 2010 marcou a retomada do processo de discussão dos rumos da Política Nacional de Saúde Mental. Nesse ano, realizou-se a IV Conferência Nacional de Saúde Mental - Intersetorial (IV CNSM-I), destacando a intersetorialidade enquanto elemento essencial para a constituição de redes de cuidado mais potentes e resolutivas.

Os nove anos que separaram a III Conferência Nacional de Saúde Mental (em 2001) e a realização da IV CNSM-I indicaram o avanço na implementação da Reforma Psiquiátrica brasileira, seja através dos mais de 1.500 Centros de Atenção Psicossocial (CAPS) hoje em funcionamento ou da realização da Marcha dos Usuários da Saúde Mental, ocorrida no dia 30 de setembro de 2009, em Brasília. Cerca de 2.300 pessoas participaram da manifestação, reivindicando, entre outras ações, a convocação da Conferência para 2010.

Todo esse movimento sinaliza que uma série de importantes mudanças vem ocorrendo na sociedade brasileira, quando antigos fantasmas manicomiais - isolamento, passividade, tutela, impotência - começam a ser exorcizados, possibilitando maiores e melhores interlocuções entre os ditos 'loucos' e a vida em sociedade. Nesse sentido, a relação com a loucura vem sofrendo modificações, conforme o nível de aprofundamento das mudanças sociais, pressionadas pelo movimento da Reforma Psiquiátrica, o que levou à construção de uma entre as mais de 1.021 teses aprovadas na plenária final da IV CNSM-I:

\section{[...] é necessário adotar um modelo de saúde} humanizado que considere o cuidado integral e a ativa participaçáo de todos, principalmente a dos próprios usuários, na elaboração e condução dos seus projetos terapêuticos, fortalecendo o 'protagonismo social', no sentido de desenvolver autonomia e autodeterminação. (BRASIL, 2010, p. 63).

Trata-se de um protagonismo que vem mostrando sua cara, escancarando a importância e a necessidade de maiores discussóes e pesquisas acerca desse elemento fundamental à construção do que aponta a proposta acima: "[...] cuidado integral e a ativa participação de todos [...]” (BRASIL, 2010, p. 63).

Desse modo, buscamos neste artigo apresentar e discutir algumas contribuiçóes, provenientes da pesquisa de mestrado de um dos autores, acerca do tema da participação social e do protagonismo de usuários de saúde mental. Essa problemática, já de início cabe ressaltar, encontra-se atrelada a um dos principais desafios enfrentados hoje pela Reforma Psiquiátrica: o risco de uma institucionalização cronificada e cronificadora dos serviços substitutivos (BARROS, 2003; PANDE; AMARANTE, 2011).

Embora tenhamos avançado no terreno macropolítico, através de conquistas importantes, como a Lei 10.216/2001, que redirecionou o modelo de atenção à saúde mental, promovendo a instalação da rede substitutiva do hospital psiquiátrico, ainda enfrentamos os perigos da reprodução da instituição invisível (manicomial) nos novos equipamentos, como CAPS, criados para romper a histórica lógica tutelar de atenção à pessoa portadora de sofrimento psíquico.

É nesse sentido que destacamos a advertência apontada por Barros (2003, p. 199), quando afirmava que corremos o risco de que "[...] a necessária institucionalidade dos CAPS se transforme em institucionalização cronificada e cronificadora, reproduzindo o asilamento do qual se quer escapar". Ou seja, não basta apenas avançarmos na formulação e na aprovação de programas e políticas públicas de saúde mental se não atentarmos para a dimensão micropolítica de produção de subjetividade.

Importante aqui atentarmos para o tratamento dado, ao longo deste estudo, aos conceitos de macro e micropolítica - ou, também, molar e molecular que muito comumente sâo tomados numa equivocada relação binária, como se fossem mutuamente excludentes, moralmente opostos, quando na verdade são forças componentes de um mesmo processo de subjetivação. Para os esquizoanalistas Gilles Deleuze (apud GUATTARI, 2010) e Félix Guattari (2010), o nível macropolítico (molar) corresponde às estratificações que delimitam objetos, sujeitos, representaçóes, leis e sistemas de referência. Já o micropolítico (molecular) 
indica os fluxos, devires, intensidades, as formaçóes do desejo no campo social. Não temos de um lado (molar) manicômios e leis que encarceram e de outro (molecular) uma micropolítica libertária. O que temos são jogos de forças múltiplas, relaçôes de poder que produzem modos de viver, desejos de clausura e de liberdade em embates intensos na mesma sociedade, nos mesmos corpos, erigindo e sustentando instituiçóes, sujeitandonos, insurgindo-se, subjetivando-nos.

Nas palavras de Guattari (2010):

Essa oposição entre molar e molecular pode ser uma armadilha. Eu e Gilles Deleuze sempre tentamos cruzar essa oposição com uma outra, a que existe entre micro e macro. As duas são diferentes. O molecular, como processo, pode nascer no macro. O molar pode se instaurar no micro. [...] Esse tipo de modelo nos mostra como a produção molar de subjetividade se acompanha necessariamente de uma negociação minima de processos moleculares. (GUATTARI; ROLNIK, 2010, p. 150-151).

Ou seja, o uso desses conceitos auxiliou-nos a compreender o complexo jogo de forças e agenciamentos que compóe os processos de subjetivação contemporâneos, especialmente no terreno das políticas públicas de saúde mental, contribuindo para o entendimento - ainda que incipiente - de que "[...] os problemas se colocam sempre e ao mesmo tempo nos dois níveis" (GUATTARI; ROLNIK, 2010, p. 156).

Desse modo, o momento atual da reforma, através de seus principais movimentos de luta antimanicomial, tem defendido a importância da "[...] redefinição do lugar do 'sujeito da diferença' na sociedade [...]” (TORRE; AMARANTE, 2001, p. 83, grifo do autor), com o intuito de construir uma política de saúde mental atenta às dívidas históricas contraídas juntamente por esse segmento da população brasileira. Nessa construção, a participação cidadã do usuário configura-se como poderosa arma contra as amarras institucionais que engessam a potência instituinte dos embates com o que se julga a loucura em nossa sociedade. As possibilidades concretas para que uma participação protagonista se realize no cotidiano dos serviços substitutivos em saúde mental, entretanto, dependem de um conjunto de processos institucionais, econômicos, políticos e subjetivos, que precisam ser identificados a fim de se tornarem objeto de intervenção militante e de investigações implicadas. Esse foi o intuito da pesquisa aqui relatada, cujo objetivo maior de contribuição com o processo de reforma psiquiátrica, em curso no país, justifica a realização do campo no município do Rio Grande do Sul, que apresenta uma das redes de atenção psicossocial mais bem estruturadas e mais "aquecidas"1 de nosso estado.

\section{Protagonizando um percurso de pesquisa: a construção metodológica}

A pesquisa baseou-se no referencial da Análise Institucional francesa, utilizando-se do método da cartografia e configurando-se como uma pesquisa-intervenção. Segundo essa abordagem, a construção de um objeto de pesquisa encontra-se, fundamentalmente, indissociada de seu próprio percurso metodológico. Um caminhar conjunto entre pesquisador e objeto: um jogo mútuo de afetaçôes e interferências que vão dando os contornos de um objeto nunca totalmente apreensível.

Cartografar, nessa perspectiva, é apostar na potência do "hódos-meta" (PASSOS; BARROS, 2009), que propóe a inversão do método ("metá-hódos"), indicando que o percurso metodológico se faz conforme se processam os encontros e efeitos do pesquisar sobre o campo de estudos e o pesquisador, sem traçar, antecipadamente, os possíveis caminhos e resultados para a pesquisa. A pesquisa adquire, desse modo, um caráter de intervenção, visto considerar "[...] a inseparabilidade entre conhecer e fazer, entre pesquisar e intervir: toda pesquisa é intervenção" (PASSOS; BARROS, 2009, p. 17).

A expressão faz alusão às "redes quentes" e "redes frias" que Passos e Barros (2004) utilizam para se referir à diferença entre as relações e os debates ocorridos no Fórum Social Mundial de Porto Alegre e no Fórum Econômico Mundial de Davos, eventos cronologicamente paralelos e politicamente contrapostos em que o tema das redes é colocado em questão. 
O conceito de analisador, que, para Lourau (1995), evidencia a dinâmica invisível de forças que perpassam as instituiçóes, tornou-se importante ferramenta de pesquisa ao possibilitar a enunciação do tensionamento instituído-instituinte e a discussão de algumas cenas e situaçóes analisadoras do tema pesquisado. Um exemplo disso, nessa trajetória específica de investigação, aparece nas formulações viabilizadas pela participação dos pesquisadores nas conferências de saúde mental, ocorridas ao longo do ano, em que a pesquisa de campo foi se desenrolando. Outra ferramenta importante para esta abordagem de pesquisa, que assumiu especial relevância nesse processo, foi o uso do diário de campo enquanto instrumento capaz de acompanhar os sutis processos de inserçáo no campo empírico. Nele, foram registrados os encontros, observações, falas e estranhamentos a fim de, mais do que apenas compor registros de pesquisador, compor a própria produçáo do conhecimento acerca da participação em saúde mental para os atores que participaram do processo: pesquisadores, usuários e trabalhadores que possam pensar-intervir na rede de saúde em que se inserem com outra condição/qualificação, munidos desse saber que deixa de ser apenas um saber acadêmico para uso pessoal e restrito a um seleto grupo de acadêmicos.

A pesquisa foi conduzida em um município da fronteira oeste do Estado do Rio Grande do Sul, através da inserção de um dos pesquisadores em dois espaços instituídos de participação para o usuário: 1) Associação dos Usuários, Familiares e Militantes da Saúde Mental; 2) Assembleia dos Usuários, reunião semanal dos usuários em um dos CAPS do município.

Além da participação nas reuniōes da associação e da assembleia dos usuários, foram realizadas entrevistas semiestruturadas com usuários, trabalhadores e gestores do serviço de saúde mental, que seráo apresentadas através de breves trechos de depoimentos selecionados a partir do critério de enunciação do tema-foco do artigo em questão ${ }^{2}$.

\section{Participação social e saúde mental: das agonias de um lutador}

A noção de inclusão e participação da sociedade civil na formulação e no controle das políticas públicas no Brasil é ainda muito incipiente. Comemoramos, em 2011, os recentes 23 anos da promulgação da Constituição Federal de 1988, cujo artigo 196 instituiu a saúde enquanto direito de todos e dever do Estado; e o artigo 198 determinou a participação da comunidade enquanto diretriz constitutiva do Sistema Único de Saúde (SUS).

É através da Lei 8.142, de 28 de dezembro de 1990, que a participação social é garantida legalmente, criando-se as principais instâncias de inserção e participação de representantes da população na construção da política de saúde nacional: as conferências e os conselhos de saúde.

No entanto, sabemos que apenas a institucionalização desses fóruns participativos não garante, por si só, a efetiva realização dos objetivos principais desses espaços democráticos: "[...] avaliar a situação de saúde e propor as diretrizes para a formulação da política de saúde nos níveis correspondentes [...]" (no caso das conferências) e "[...] atuar na formulação de estratégias e no controle da execução da política de saúde na instância correspondente [...]" (para os conselhos de saúde) (BRASIL, 1990).

Em amplo artigo acerca da situação da participação social no Brasil, Goulart (2010) aponta alguns dos principais dilemas enfrentados para a efetivação desse princípio do SUS:

\section{[...] devem os conselhos se constituir como fó- runs autônomos, plenárias de debates, assem- bleias permanentes, etc., destinadas ao apro- fundamento politico, conceitual, filosófico dos temas sanitários, mas cujas decisóes terão apenas implicaçóes remotas (se tanto) sobre a condução do sistema de saúde? Ou, de forma oposta, o que realmente importa náo seria}


influenciar de fato, com foco na práxis da gestão? (GOULART, 2010, p. 30).

$\mathrm{O}$ autor destaca um acentuado processo de burocratização dos conselhos de saúde, resultando em uma

\section{[...] espécie de reinvenção da tutela, da subal-} ternidade e da dependência na relação entre Estado e sociedade. Os conselhos passam a agir como meros espaços de disputa por recursos públicos. (GOULART, 2010, p. 22).

Quanto a isso, acreditamos que o depoimento abaixo ilustre a questão:

[...] eu acho que esses locais instituidos, por exemplo, o próprio serviço de saúde mental, a associação dos usuários, o conselho de saúde, eles não podem ser instituiçóes assim muito burocráticas, tem que ter essa coisa do cuidado, né? de estimular as pessoas, estimular a autonomia, e eu acho que o maior entrave é isso. Eu acho que esse seria assim, dos movimentos sociais que eu vejo, que os conselhos de saúde, às vezes, se tornam muito burocráticos. Eles não trabalham a questão da grupalidade, do associativismo, da associaçâo, da importância das ideias de cada um para formar o todo. Não sei, eu vejo meio por ai. (trabalhador de saúde) ${ }^{3}$.

Em outras palavras, o princípio da participação social constrói-se coletivamente, associado ao encontro e à disputa de forças, poderes e ideias, e não apenas restrito ao âmbito de espaços formais instituídos. Ou, segundo o depoimento de outro participante:

Participação é interagir, é trocar, dialogar. É nem sempre ter razão, sabe? [...] uma das coisas que eu mais aprendi, trabalhando em saúde mental, foi desenvolver a flexibilidade. É respeito também. Então, acho que a participação funciona por aí: ter essa abertura, náo ter esse preconceito, de ir construindo conforme aquilo que vai aparecendo. (trabalhador de saúde).

Neste ponto, cabe retomar as duas dimensóes anteriormente discutidas para a análise das falas dos entrevistados: a do plano macropolítico, referente à formação dos conselhos, conferências, garantias de leis, daquilo que está instituído e formalizado socialmente; e outra que inclui o plano micropolítico, das relaçóes de forças entre sujeitos desejantes, compondo formas de se subjetivar, por exemplo, mais ou menos participativas. Um plano que deixa mais evidente a dimensão da cidadania (plano jurídico) e outro que ressalta a dimensão dos processos de singularização (plano subjetivo). São concepções que diferem sem, contudo, divergirem, e que deveriam ser compreendidas como necessárias e complementares uma à outra.

Dito de outra forma:

[...] os fóruns não existiriam não fosse a estrutura institucional que os criou e somente haverá participação se houver organização da sociedade civil. Em certos casos podem ocorrer resistências das autoridades municipais de saúde em relação à participação dos usuários e mesmo assim ela ocorrer em função da pressão dos movimentos sociais. (CÔRTES, 2002, p. 38).

Desse modo, entendemos a participação social enquanto processo de afirmação de singularidades possíveis, forjado nos encontros, parcerias, embates e discussóes que se dão no cotidiano do trabalho em saúde, tanto nos espaços instituídos formais, criados para que as pessoas participem levando suas reivindicações e delegando poderes, quanto nos encontros que compóem o dia a dia da vida de um usuário da saúde mental em um Centro de Convivência Diária, como efeito dos processos instituintes que aí possam se produzir. Um usuário, deliberando acerca das rotinas do CAPS na

\footnotetext{
Utilizamos o recurso de grifar em itálico os depoimentos literais dos entrevistados, destacando, sempre ao final dos trechos, a categoria a qual ele pertencia (trabalhador, gestor ou usuário da saúde mental)
} 
Assembleia do Conselho Local, votando uma tese na Conferência Nacional de Saúde Mental ou definindo seu Plano Terapêutico com a equipe que lhe cuida na unidade de saúde, pode ter, do ponto de vista da micropolítica do processo de cuidado, a mesma potência transformadora de vidas. Trata-se, portanto, de apostarmos nesse plano subjetivo - movimentos de resistência e criação - em que a análise micropolítica “[...] consistiria, exatamente, em tentar agenciar os processos de singularização no próprio nível de onde eles emergem [...]" (GUATTARI; ROLNIK, 2010, p. 152), ou seja, buscando enfrentar a ambiguidade inerente a todo processo de institucionalização na perspectiva de que se encontrem 'novas saídas' para os riscos de enrijecimento próprios dos movimentos da vida. De forma sistemática, parece-nos que é isso que os usuários expressam quando fazem incluir a seguinte reivindicação entre as teses aprovadas na IV CNSM-I:

\section{A ampliação da participação da população nas} decisóes do cotidiano dos serviços e nas instâncias de controle social deve incluir estratégias que incentivam o fomento, a capacitação $e$ qualificação das associaçóes e movimentos de saúde mental, organizados por representaçáo e o incentivo à promoção de reunióes de usuários e familiares, em assembleias participativas nos serviços de saúde mental. As capacitaçóes para o exercício do controle social devem contemplar temáticas de saúde mental e serem feitas em parcerias com universidades. Para tanto seria fundamental a inclusão dos diferentes atores da rede de saúde mental, a sensibilização dos profissionais de saude para integrarem os conselhos, o convite a outros movimentos sociais e estímulo à organização de todos os atores em associaçôes, conselhos e participação nas conferências. (BRASIL, 2010, p. 38).

A partir disso, a problemática do protagonismo insere-se enquanto questáo pertinente ao tema do controle social e pode ofertar um precioso instrumento conceitual e metodológico para o enfrentamento dos riscos das cristalizaçóes institucionais, que figuram na complexa trama de impasses a serem superados para a realização dessa fundamental diretriz constitucional de participação no sistema de saúde. Esse tema ganha ainda maior relevância quando se trata deste peculiar usuário do SUS, que ainda carrega uma herança de preconceitos e estigmas associados à loucura, conforme a fala de um usuário: "[...] fico triste de ver que muitos usuários não têm 'voz ativa' de verdade em assuntos pertinentes à saúde mental”.

Para a dramaturgia grega, ser o protagonista sinalizava ser o primeiro a entrar em cena. Por isso, ainda hoje, a etimologia da palavra protagonista guarda algo dessa disputa, pois 'proto' significa primeiro, principal, e 'agón' significa luta, disputa, discussão. $\mathrm{O}$ primeiro a falar na 'ágora' grega, portanto, o 'protoagonista', é justamente aquele que anuncia o que se irá discutir, o primeiro a pôr aquilo que está em disputa, em discussão, em cena. Não será mesmo isso - aquilo que não pode calar - que o usuário da saúde mental anuncia em sua demanda/agonia participativa? O que 'precisa' ser posto na roda?

Trazer essa metáfora para o cenário da Reforma Psiquiátrica sugere que, quando se trata de uma personagem como o 'louco', esse lugar relativiza-se. Ser o primeiro a falar/participar/debater ainda implica enfrentar desafios que carregam antigos atavismos manicomiais. Por isso, a importância da construção de territórios onde o protagonista possa, realmente, exercitar essa experimentação subjetiva de 'entrar em cena'.

\section{Protagonismo e saúde mental: a potência de um coletivo}

Não façam nada pra nós, sem nós!

Essa fala, enunciada por um usuário durante um dos encontros da assembleia no CAPS, ajudou-nos a problematizar que protagonismo é esse que buscamos estudar e que se discute em saúde mental e nos encontros do movimento antimanicomial. Conforme participávamos das reunióes da associação e da assembleia dos usuários, percebemos que a formação desses 
espaços participativos constituía-se como algo a mais que meros encontros de grupos de usuários.

O espaço assembleia, por exemplo, composto por um grupo de 20 a 30 usuários, com encontros semanais, caracteriza-se por ser uma forma participativa na qual todos os usuários do CAPS são incentivados a participar, tendo por objetivo a discussão de temas e assuntos do cotidiano do serviço, além de demandas trazidas pelos próprios usuários.

Nas reunióes das quais participamos, os assuntos giravam em torno de questóes voltadas ao relacionamento de uns com os outros, além de algumas atividades desenvolvidas no CAPS e na cidade: participação nas feiras do livro e da saúde do município; apresentaçôes de capoeira; atividades em projetos de educação vinculados ao CAPS e participação nas demais oficinas realizadas pelo serviço. Os usuários relataram histórias de vida ocorridas antes e depois de começarem a frequentar o CAPS. Histórias de abandono, violência, internaçôes em hospitais psiquiátricos por aí afora. Com a vinculação às atividades do CAPS, consideraram-se seres humanos respeitados: "[...] me sinto feliz aqui. É minha segunda casa! [...] sem a saúde mental, hoje nós não tinha ninguém".

Ao longo dos encontros, fomos percebendo que formam um grupo bem unido. Muitos se conhecem há bastante tempo, se divertem, brincam e caçoam uns dos outros, mas também se apoiam mutuamente: “[...] eu tenho liberdade de ir e vir. Tu percebe que existe aqui uns laços de grande afetividade, respeito, um excelente trabalho nas oficinas, de integração, né? de relação interpessoal" (usuário).

A partir desses encontros nas assembleias, a possibilidade de protagonizar, atrelada à existência de espaços participativos, começou a se delinear mais claramente, especialmente após uma das entrevistas com um usuário membro da associação dos usuários do município:

\section{[...] dentro da associação existe, assim [...] um} grupo de pessoas que eu já conheço há mais tempo. São todos conhecidos agora. Isso ajuda muito, porque quando eu entrei na associação [...] bah! hoje são pessoas que eu olho e tu não te sente assim [...] sufocado, sabe?! É diferente

\section{de fazer uma terapia em grupo, que eu fui fazer uma vez e náo deu certo.}

Isso indicou-nos uma busca por pertencimento, pela constituição de um coletivo que ultrapassa as dimensões de apenas um grupo terapêutico ou reunião de usuários: a importância de uma vinculação afetiva, que se estabelece enquanto processo e efeito de subjetivação. Indicou-nos a demanda pela constituição de um território subjetivo onde o usuário possa experimentar, talvez pela primeira vez, a capacidade de pensar e decidir por si só uma trajetória singular de vida.

Nesse sentido, estamos nos referindo ao conceito de coletivo, visto como plano relacional, constituído 'entre' indivíduo e sociedade, de agenciamento, logo, produtor de subjetividade, como esclarece Escóssia (2009):

\section{[...] um conceito de coletivo cuja definição não} se dá por oposição ao individuo, pois não se confunde nem com um social totalizado nem com a interação entre seres já individuados. Trata-se de um coletivo a ser apreendido a partir de dois planos distintos, porém inseparáveis. Planos que se cruzam desfazendo as binaridades: o plano das formas e o plano das forças. $O$ plano das formas é o plano de organização e desenvolvimento das formas (DELEUZE, PARNET, 1998), plano do instituido (LOURAU, 1995) e da Lei, e concerne às formas já constituidas - individuais ou coletivas. [...] O plano das forças é o plano de constituição/criação das formas - individuais e sociais. Também definido como plano de imanência (DELEUZE, PARNET, 1998), plano do instituinte (LOU$R A U, 1995)$ ou plano de relaçóes (VEYNE, 1982). (ESCÓSSIA, 2009, p. 690).

Uma compreensão, portanto, de coletivo enquanto plano de existência fértil para a experimentação de maneiras outras de viver a vida. Isso remete a uma sutil, porém significativa, diferenciação, que aqui nos interessa especialmente, entre os termos autonomia e protagonismo, ambos largamente explorados entre as 
reivindicações mais recorrentes das teses aprovadas na IV CNSM-I.

A etimologia da palavra autonomia - onde 'auto' significa próprio, si mesmo, e 'nomos' norma, regra, lei - sugere pensar que autonomia encontra-se ligada à noção de indivíduo capaz de se autodeterminar, aquele que produz e vive de acordo com normas próprias, ou seja:

\section{[...] conduz o pensamento imediatamente à} ideia de liberdade e de capacidade de exercício ativo de si, da livre decisão dos indivíduos sobre suas próprias açóes e às possibilidades e capacidades para construirem sua trajetória de vida. (FLEURY-TEIXEIRA et al., 2008, p. 2118).

A autonomia, vista desse modo, sugere a capacidade, quase que pronta e imediata, de saber se autodeterminar, de, ativamente, traçar formatos e projetos de vida. Porém, essa compreensão mais rasa da autonomia desconsidera, muitas vezes, que esse projeto de "autogoverno" está colado em processos de subjetivação muito próximos das amarras de que justamente pretende se libertar: da solidão individualista. Nessa perspectiva, o tâo promulgado fomento à autonomia pode se tornar muito mais uma bandeira de luta de movimentos políticos instituídos para esses fins do que propriamente um exercício de pensar sobre si mesmo, de (re)criar regras e modos de vida compatíveis com os sonhos singulares de cada um. Além de corrermos o risco de reproduzir a instituição manicomial sob outra roupagem, como bem alertam Pande e Amarante (2011, p. 2075): “[...] os serviços podem, a um só momento, cronificar, restringir, segregar, proteger, bem como libertar, favorecer autonomia, cidadania e protagonismo.”.

Em contrapartida, o conceito de protagonismo emergiu, em muitas das situaçóes promovidas pela pesquisa, como muito próximo àquilo que os atores da Reforma Psiquiátrica escutados referiam como efeito experimentado em suas boas experiências de participação: [...] me sentir fazendo parte... aprender meu valor... poder ser útil para outros... resgatar a própria vida [...] foram algumas das expressões utilizadas que se referiam à dimensão coletiva da experiência participativa. Ou seja, parece-nos que o exercício de protagonizar, assim sugerido, potencializaria as possibilidades de criação das próprias normas de vida, preparando o terreno para tal empreendimento:

Se ele [Associação dos usuários] for um espaço verdadeiro, no qual eu possa divergir, opinar, pensar, concordando ou discordando, acho de extrema importância. Pelo menos dentro da associação e em alguns setores do serviço existe. Eu acho de extrema importância pra qualquer pessoa poder participar. Nós temos colegas dentro da associação que são, assim, extremamente difíceis de lidar, mas estão ali participando [...]. (usuário).

Nesse sentido, esse depoimento aproxima-se daquilo que PASSOS; BARROS (2004) propóem como a interface entre clínica e política, ressaltando o potencial terapêutico de um coletivo:

[...] ai nos encontramos com modos de produção, modos de subjetivação e não mais sujeitos, modos de experimentação/construção e não mais interpretação da realidade, modos de criaçáo de si e do mundo [...]. Entendemos a experiência clínica como a devolução do sujeito ao plano da subjetivaçáo, ao plano da produçáa que é plano do coletivo. O coletivo, aqui, bem entendido, não pode ser reduzido a uma soma de indivíduos ou ao resultado de um contrato que os individuos fazem entre si. Coletivo diz respeito a este plano de produçáo, composto de elementos heteróclitos e que experimenta, todo o tempo, a diferenciação. [...] No coletivo não há, portanto, propriedade particular, pessoalidades, nada que seja privado, já que todas as forças estão disponiveis para serem experimentadas. (PASSOS; BARROS, 2004, p. 165-166).

Dessa forma, a insurgência do coletivo, assim entendido, afirma-o como um dispositivo participativo propício e potente ao exercício de protagonismo em 
saúde mental. $\mathrm{O}$ coletivo emerge aí como elemento capaz de favorecer um tipo de participação que, em vez de reforçar as marcas do individualismo crescente numa sociedade excludente, é capaz de reafirmar a possibilidade de todo sujeito, e qualquer sujeito, em algum momento, ser o primeiro a se enunciar: 'proto-agonizar'. O coletivo, como dispositivo de inclusão, torna-se, assim, um conceito especialmente caro, ainda mais quando se trata de falar de participação social daqueles que carregam a marca da segregação e da alienação em nossa sociedade.

\section{Considerações Finais}

A pesquisa aqui sintetizada partiu do problema acerca de quais formas ou mecanismos de participação em saúde mental potencializariam o protagonismo dos usuários. O desafio foi cartografar o processo micropolítico da participação, tomando por base as possibilidades de esses espaços instituídos abrirem-se aos movimentos instituintes e cederem lugar às forças divergentes, às forças que pedem transformação: um outro lugar social.

A questão, portanto, era essencialmente problematizar que tipo de composição participativa permitiria o fomento do protagonismo de um usuário, que, justamente por ser 'usuário da saúde mental', carrega as marcas da exclusão, entre outras tantas justificativas clínico-jurídicas, na definição, como mentalmente incapazes. Logo, pessoas desprovidas de qualquer capacidade de gerirem sua própria vida. Quem dirá de 'falar em primeiro lugar' sobre a vida em comum, enunciar-se em nome de um coletivo, pronunciar-se quanto à formulação de normas para a vida na 'pólis'?

Nesse sentido, discutir qual participação efetivamente temos construído na saúde mental coletiva indica a necessidade de mais pesquisas e debates em torno da 'participação possível', a ser construída nesse segmento do SUS. Mas indica, também, a urgência do debate em torno da 'participação desejável', já que temos garantido espaços de participação social que não necessariamente resultaram em experiências de incremento à capacidade das pessoas de interferirem nos rumos da própria vida.
Além dessa concepção de base - que deve necessariamente incluir dimensóes macro e micropolíticas -, pensar as possibilidades de participação com protagonismo deve levar em conta, de acordo com a perspectiva institucionalista, um conjunto de processos institucionais, econômicos e políticos, com o intuito de diminuir certo entendimento frequentemente reduzido à visão dos atores que a induzem e de suas concepções. Por exemplo, algumas discussões dos participantes muitas vezes ficaram centradas em um viés eminentemente corporativo, em torno da afirmação e da defesa de interesses muito mais da esfera de um segmento específico, que náo necessariamente fomentavam a possibilidade de o usuário engatar-se nessa mesma discussão e exercitar a possibilidade de 'entrar em cena'. Acompanhamos isso nas definiçóes acerca das teses a serem defendidas para conferências de saúde mental a cada etapa, nas decisóes acerca da logística necessária para viabilizar a participação dos usuários nas próprias conferências (decisóes materiais básicas relativas à alimentação, ao transporte, custeio dos acompanhantes, por exemplo), que, em última análise, repetem a demanda por hierarquia elementar que o usuário de saúde mental experimenta a cada dia. Argumentos que soavam como favoráveis aos usuários, mas, na maioria das vezes, eram oriundos do posicionamento político-institucional do segmento trabalhador em saúde. Em outras palavras, um modo participativo que, em determinados momentos, solapava a viabilidade de o usuário sentir-se de qualquer forma incluído.

Figueiró e Dimenstein (2010), também debatendo esse tema na relação entre trabalhador e usuário em saúde mental, relatam uma cena em que uma usuária perguntou o porquê de algumas mudanças feitas nas oficinas terapêuticas, e a resposta obtida foi que 'eles' (trabalhadores) haviam pensado propor algumas atividades novas, de acordo com a concepção 'deles' (dos trabalhadores). E os autores comentam:

Isso mostra de onde partiram as mudanças, bem como torna visivel algumas linhas de força que colaboram para a manutenção de determinadas práticas, que se atualizam, muitas 
vezes, bem distantes das posiçóes dos usuários. (FIGUEIRÓ; DIMENSTEIN, 2010, p. 435).

A mesma assimetria também foi possível constatar em nossa pesquisa, indicando processos que constrangem o protagonismo e, consequentemente, favorecem a manutenção da histórica passividade dos usuários de saúde mental. Ou seja, questóes de disputa de interesses e hierarquização nas relações de poder entre profissionais e usuários, bem como o enrijecimento dos modos de conduzir o processo participativo são capazes de evidenciar certos riscos de uma possível institucionalização cronificadora, sinalizando fatores que podem reduzir (ou até mesmo inviabilizar) as possibilidades de protagonismo em saúde mental.

Entretanto, na contramão disso tudo, foi possível também constatar processos que evocaram uma sensação de caos, de ruptura de uma ordem e de um tipo de participação que, idealmente, acreditávamos poder encontrar nesses espaços. Conforme participávamos de alguns encontros, esses espaços, em certos momentos, indicaram uma abertura significativa a processos de singularização. A pesquisa constatou que o espaço assembleia dos usuários carregava a potência de um coletivo capaz de fomentar momentos de protagonismo, necessários de serem mais bem aproveitados pelos atores todos que dele participam, e, talvez, principalmente, pelo serviço, que ainda não percebe devidamente a riqueza da ferramenta terapêutica que ali se produz.

A construção, portanto, de espaços participativos potentes para que isso possa ocorrer cada vez mais e de melhores formas vincula-se à principal tese aqui defendida: o entendimento de que o protagonismo em saúde mental dependeria da garantia de exercícios efetivamente coletivos de confronto livre de ideias, espaços em que as forças instituintes se debatam com as formas instituídas de participação social (a inter-relação molar e molecular), e permitam, cada vez mais, que normas sejam experimentadas e discursos sejam enunciados em uma 'ágora' capaz de acolher toda a diversidade humana, mesmo na diferença radical que a loucura escancara.

Com isso, estamos dizendo que o resgate da dimensão heroica de pronunciar-se em um confronto público - que o termo protagonismo guarda - requer a constituição de espaços em que os usuários possam experimentar a capacidade de pensar, sentir e decidir sobre suas vidas singulares em meio ao coletivo que constituem e que os constitui subjetivamente. Estamos, pois, falando de uma costura micropolítica do processo participativo, que não se dá a priori nos espaços instituídos para que ele aconteça, mas pode se dar, inclusive, neles.

Mesmo sem ter sido 'a primeira a falar' desse debatido tema da participação social na saúde mental, essa pesquisa teve a pretensão de problematizar a temática das formas e forças contidas nos espaços participativos, de forma a constituir-se como mais um dispositivo para que os usuários da saúde mental se façam efetivamente protagonistas, sejam menos silenciados e alienados de sua força e potência. Que o usuário possa, realmente e cada vez mais, ser o ator principal, capaz de criar caminhos para si e, com isso, impulsionar a revoluçáo de sentidos que se pretende alcançar com o movimento de nossa Reforma Psiquiátrica. Que o 'nada mais para nós, sem nós!' deixe de ser um pedido isolado de um usuário escutado em uma pesquisa em saúde mental e se torne um imperativo ético para toda política pública de nosso país.

\section{Referências}

BARROS, R. B. Reforma Psiquiátrica Brasileira: resistências e capturas em tempos neoliberais. In: CONSELHO FEDERAL DE PSICOLOGIA (Org.). Loucura, Ética e Política: Escritos Militantes. São Paulo: Casa do Psicólogo, 2003.p. 196-206.

BRASIL. Sistema Único de Saúde. Conselho Nacional de Saúde. Comissão Organizadora da IV Conferência Nacional de Saúde
Mental - Intersetorial. Relatório Final da IV Conferência Nacional de Saúde Mental - Intersetorial, 27 de junho a 1 de julho de 2010. Brasília: Conselho Nacional de Saúde/Ministério da Saúde, 2010.

Congresso Nacional. Lei 8.142, de 28 de dezembro de 1990. Dispõe sobre a participação da comunidade na gestão do Sistema único de Saúde e sobre as transferências 
intergovernamentais de recursos financeiros na área de saúde e dá outras providências. Brasília: Ministério da Saúde, 1990.

CÔRTES, S. V. Construindo a possibilidade da participação dos usuários: conselhos e conferências no Sistema Único de Saúde. Sociologias, Porto Alegre, ano 4, n. 7, p. 18-49, jan./jun. 2002.

ESCÓSSIA, L. O coletivo como plano de criação na Saúde Pública. Interface - Comunicação, Saúde, Educação, Botucatu, v. 13, supl. 1, p. 689-694, 2009.

FIGUEIRÓ, R. A.; DIMENSTEIN, M. O cotidiano de usuários de CAPS: empoderamento ou captura? Fractal: Revista de Psicologia, Niterói, v. 22, n. 2, p. 431-446, maio/ago., 2010.

FLEURY-TEIXEIRA, P. et al. Autonomia como categoria central no conceito de promoção de saúde. Ciência \& Saúde Coletiva, Rio de Janeiro, v. 13, supl. 2, p. 2.115-2.122, 2008.

GOULART, F. Dilemas da participação social em saúde no Brasil. Saúde em Debate, Rio de Janeiro, v. 34, n. 84, p. 18-32, jan./mar. 2010.
GUATTARI, F.; ROLNIK, S. Micropolítica: cartografias do desejo. Petrópolis, Rio de Janeiro: Vozes, 2010.

LOURAU, R. A Análise Institucional. Petrópolis, Rio de Janeiro: Vozes, 1995. 118p.

PANDE, M. N. R.; AMARANTE, P. Desafios para os CAPS como serviços substitutivos - a nova cronicidade em questão. Ciência \& Saúde Coletiva, Rio de Janeiro, v. 16, n. 4, p. 2067-2076, 2011.

PASSOS, E.; BARROS, R. B. A cartografia como método de pesquisaintervenção. In: PASSOS, E.; KASTRUP, V.; DA ESCÓSSIA, L. (Orgs.) Pistas do método da cartografia: Pesquisa-intervenção e produção de subjetividade. Porto Alegre: Sulina, 2009. p.17-31.

Clínica, política e as modulações do capitalismo. Revista Lugar Comum, Rio de Janeiro, n. 19-20, p. 159-171, jan./jun. 2004.

TORRE, E. H. G.; AMARANTE, P. Protagonismo e subjetividade: a construção coletiva no campo da saúde mental. Ciência \& Saúde Coletiva, Rio de Janeiro, v. 6, n. 1, p. 73-85, 2001.

Recebido para publicação em Novembro/2011

Versão definitiva em Junho/2012

Suporte financeiro: não houve

Conflito de interesse: inexistente 